\title{
Electrodeposition of Sn-In Alloys Involving Deep Eutectic Solvents
}

\author{
Liana Anicai $^{1, *(\mathbb{D}}$, Aurora Petica ${ }^{1}$, Stefania Costovici ${ }^{2}$, Calin Moise ${ }^{1} \mathbb{D}$, Oana Brincoveanu ${ }^{1}$ and \\ Teodor Visan ${ }^{1,3}$ \\ 1 Center of Surface Science and Nanotechnology, University Politehnica of Bucharest, Splaiul Independentei \\ 313, 060042 Bucharest, Romania; aura_p25@yahoo.com (A.P.); calin.moise@cssnt-upb.ro (C.M.); \\ oana.brincoveanu@cssnt-upb.ro (O.B.); t_visan@chim.upb.ro (T.V.) \\ 2 Mibatron SRL-Bucharest, Doamna Ghica Str. No.1, 022821 Bucharest, Romania; pcbdept@gmail.com \\ 3 Department of Inorganic Chemistry, Physical Chemistry and Electrochemistry, University Politehnica of \\ Bucharest, 132 Calea Grivitei, 010737 Bucharest, Romania \\ * Correspondence: lanicai@itcnet.ro; Tel.: +40-723-685-319
}

Received: 1 November 2019; Accepted: 27 November 2019; Published: 28 November 2019

\begin{abstract}
Tin-indium alloys represent attractive lead-free solder candidates. They show lower values of melting point than pure indium, so that they are investigated as materials with significant applications potential in the electronic industry. Electrodeposition is a very convenient route to prepare Sn-In alloys. The paper presents several experimental results regarding the electrodeposition of Sn-In alloy coatings involving deep eutectic solvents (DESs), namely using choline chloride-ethylene glycol eutectic mixtures. The influence of the main operating parameters on the $\mathrm{Sn}$-In alloy composition and characteristics are presented. Adherent and uniform Sn-In alloy deposits containing 10-65 wt $\%$ In have been obtained on $\mathrm{Cu}$ substrates. The In content was found to increase as both the In:Sn molar concentration ratio of ionic species in the electrolyte and the applied temperature increased. The use of pulsed current allowed the use of higher current densities leading to slightly higher values of In content in the alloy deposit. X-ray diffraction (XRD) analysis revealed the presence of $\mathrm{InSn}_{4}$ and $\mathrm{In}_{3} \mathrm{Sn}$ phases in agreement with the phase diagram. According to thermogravimetric analysis (TGA) measurements, values of melting points in the range of 118.6 and $127.5^{\circ} \mathrm{C}$ were obtained depending on the alloy composition. The solder joints' behavior and alloy coatings corrosion performance were also discussed.
\end{abstract}

Keywords: electrodeposition; Sn-In alloy; deep eutectic solvents; lead-free solder alloy; pulse plating

\section{Introduction}

Several years back and motivated by environmental and health concerns, the legislation regarding the end-of-life disposal and the European Union's (EU) Restriction of Hazardous Substances (RoHS) Directive determined the elimination of $\mathrm{SnPb}$ solder from all electronic applications in the EU and other countries' markets, including China, Japan, South Korea, Turkey and the United States [1,2]. Under these circumstances, the development of lead-free solder alloys attracted increased interest. Currently, a large range of solders as binary and ternary alloys have been proposed, based on $\mathrm{Sn}$ coupled with other elements such as $\mathrm{Cu}, \mathrm{Ag}, \mathrm{Zn}, \mathrm{Ni}, \mathrm{Sb}, \mathrm{Bi}$ and In [2-7].

The most common solder alloys, such as $\mathrm{Sn}-\mathrm{Ag}$ and $\mathrm{Sn}-\mathrm{Cu}$ solder alloys have melting point temperatures higher than $200{ }^{\circ} \mathrm{C}\left(221\right.$ and $227^{\circ} \mathrm{C}$, respectively) while for low-temperature soldering conditions, only $\mathrm{Sn}-\mathrm{Bi}$ and $\mathrm{Sn}-\mathrm{In}$ systems may be used, whose melting points are below $180^{\circ} \mathrm{C}(138-170$ and $118-145^{\circ} \mathrm{C}$, respectively) $[2,8,9]$. 
On the other hand, a major problem affecting reliability aspects particularly in long-life electronic applications is represented by the tin whiskers. Usually, they represent crystalline filaments $1-10 \mu \mathrm{m}$ thick and up to hundreds of microns long, which can grow from any high-Sn solder or coating, causing short circuits. Specific environmental conditions, such as power cycling, thermal, humidity conditions could cause tin whisker formation, although this is still being debated in the literature [2]. Various substitute approaches that mitigate the whiskers growth of $\mathrm{Sn}$ include the use of $\mathrm{Bi}$, of $\mathrm{Ni}$ underlayer or of conformal coatings [9-12].

Quite recently it has been shown that the addition of a certain amount of In can contribute to the elimination of whiskers growth in electrodeposited Sn on copper substrates under ambient temperature aging. Therefore, in terms of $\mathrm{Sn}$ whisker mitigation, In seems to represent a better additive than $\mathrm{Pb}[9,13,14]$. In addition, due to their physico-mechanical and chemical properties, including low melting temperature, low stress, superior thermal fatigue resistance, Sn-In alloys are suitable for making connections by soldering in the assembly of integrated circuits and micromodules [15-17]. Besides their use as lead-free solder alternative, the Sn-In alloys are also attractive as protective, antifriction and wear-resistant coatings and, more recently, as an efficient catalyst for the electrochemical reduction of $\mathrm{CO}_{2}[15,18-20]$.

Electrodeposition is a very convenient route to apply Sn and Sn alloys, due to its advantages such as compatibility with photolithography, high deposition rate, ease in extending substrate size, being environmentally benign and its good end properties [5]. However, the traditional use of aqueous electrolytes scarcely delivers the desired composition and due to the stannous oxidation problems the baths show poor stability. In the case of Sn-In alloy electrodeposition in particular, additional difficulties have been noticed mostly associated with the quite large difference between the standard electrode potentials of the $\mathrm{Sn} / \mathrm{Sn}^{2+}$ and $\mathrm{In} / \mathrm{In}^{3+}$ half-cells [9].

The electrodeposition of Sn-In alloys in aqueous solutions usually involves either strongly acidic or alkaline electrolytes, both containing alkali metal salts of carboxylic acids as chelating agents to ease the Sn deposition. A better stability and control of the plating process has been noticed in the case of alkaline baths [21]. Acidic sulfate based electrolytes have been also applied to electrodeposit Sn-In alloys, usually in the presence of several organic additives to facilitate obtaining bright coatings. [15,22]. Ozga et al. [23] studied the electrodeposition of Sn-In alloy involving a complex citrate type electrolyte with additions of PEG 3000 nonionic surfactant at $\mathrm{pH}=2.5$. Quite recently, Mahapatra and Dutta [9] reported the electrodeposition of Sn-In alloy involving a methanesulfonic acid based electrolyte which allowed coatings containing up to $20 \%$ In to be obtained. In addition, it has been concluded that alloying $\mathrm{Sn}$ with a certain percentage of In followed by a heat treatment eliminates the whiskers growth from $\mathrm{Sn}$ coatings under room temperature aging conditions.

In spite of the adequate performance, the preparation involving aqueous solutions usually suffers from some drawbacks, mainly related to the complexity and sometimes toxicity of the electrolytes formulation, the need for additives, as well as the occurrence of hydrogen evolution as secondary reaction affecting the cathodic efficiency. Moreover, to keep the chemical composition of the alloy constant during the electrodeposition process is quite challenging, mostly due to the variance in the redox potentials of the constituent metals or/and variation of deposition kinetics of one metal relative to the other one $[24,25]$.

To overcome these critical aspects, deep eutectic solvents (DESs), which are a new class of ionic liquids, have been used for the electrodeposition of a large range of metals and alloys. They possess several favorable characteristics such as low vapor pressure, wide liquid-phase range and greater electrochemical and thermal stability, low cost, and being stable against moisture, and are also considered as more environmentally friendly alternatives [25-27]. DESs are composed of binary mixtures of quaternary ammonium salts with either a hydrogen bond donor such as urea, ethylene glycol, glycerol, malonic acid, oxalic acid or a metal salt [26,28-30].

Only a few investigations related to the electrodeposition of binary and ternary Sn and/or In alloys from DESs have been reported. Gao et al. [31] studied the electrodeposition of Sn-Bi alloy 
from a choline chloride-ethylene glycol deep eutectic solvent. The results suggested the possibility of electroplating the $\mathrm{Sn}-\mathrm{Bi}$ alloys with their composition around the eutectic point. The influence of the choline chloride eutectics composition on the properties of Sn and Sn-Ni alloys has been also evidenced in [32]. In the case of Zn-Sn alloys, their morphology and composition can be changed by judicious choice of the DES containing electrolyte composition [33]. Shaban et al. [24] successfully electrodeposited Sn-Ag alloys involving choline chloride-ethylene glycol eutectic mixtures. The concentration of silver ions in the DES electrolyte was the main factor affecting the crystallites size and morphology of the $\mathrm{Sn}-\mathrm{Ag}$ alloys.

Recently, the electrodeposition of In on $\mathrm{Cu}[34]$ and W $[34,35]$ substrates was reported by using the deep eutectic solvent choline chloride-ethylene glycol (1:2).

The electrodeposition of $\mathrm{Cu}-\mathrm{In}$ alloys from choline chloride-urea eutectic mixture onto Mo substrates has been reported in [36]. It was concluded that the composition of the deposited films depends on both deposition potential and on the concentration ratio of the metal cations in the ionic liquid. The same group also studied the one step electrodeposition of $\mathrm{Cu}$, In and $\mathrm{Ga}$ metals and their alloys from the choline chloride:urea eutectic mixture [37]. The morphology of the deposits depended primarily on the metal salt concentration in solution, since dendrites as well as compact layers were obtained. Moreover, the formation of the ternary alloys was found to be very limited and thus the alloying mechanism was dominated by the $\mathrm{Cu}-\mathrm{Ga}$ and $\mathrm{Cu}-\mathrm{In}$ binaries.

Very few published works discussed the electrodeposition of Sn-In alloys involving traditional ionic liquids. The group of Morimitsu and Matsunaga [38,39] investigated the electrochemical processes of $\mathrm{Sn}$, In and In-Sn in EMI-BF ${ }_{4}$-CI melts obtained by mixing of EMIC(1-ethyl-3-methylimidazolium chloride) and $\mathrm{NaBF}_{4}$ in $60: 40 \mathrm{~mol} \%$ ratio. The results obtained suggested that the deposition proceeds via an underpotential deposition of In on the Sn predeposited electrode surface. Two crystalline phases ( $\mathrm{Sn}$ and $\mathrm{InSn}_{4}$ ) have been evidenced, in which the crystallinity of $\mathrm{InSn}_{4}$ was more improved by increasing the deposition temperature to $80^{\circ} \mathrm{C}$. The same group has also reported the influence

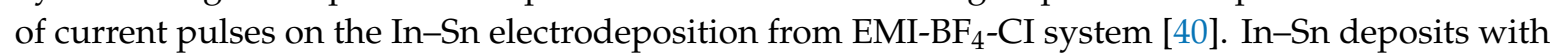
higher indium content were obtained by the pulsed technique. For electrolytes containing higher concentrations of the stannous ion, the indium content decreased with the off-time duration, probably due to the exchange reaction between indium metal in deposits and stannous ion in melt during off-time. Therefore, the required composition of the In-Sn alloy coatings may be obtained through a proper selection of the pulse parameters.

Considering the above, the present paper aims to explore the feasibility of the co-electrodeposition of Sn-In alloy coatings involving DESs, mainly using choline chloride-ethylene glycol eutectic mixtures. It is worth mentioning here that to the best of our knowledge this is the first investigation reporting the electrochemical deposition of Sn-In alloys using DES based electrolytes. The influence of the main operating parameters (i.e., the metallic ions concentration ratio, the current form: direct or pulse current, temperature) on the Sn-In alloy composition and characteristics are presented. The solderability performance as well as corrosion behavior in $0.5 \mathrm{M} \mathrm{NaCl}$ aqueous solution exposure are reported as well.

\section{Materials and Methods}

To perform experiments, choline chloride-ethylene glycol eutectic mixtures (1:2 molar ratio) (denoted ILEG), containing the metallic salts corresponding to the metal/alloy that is to be electrodeposited, were synthesized as shown in Table 1. Choline chloride $\left(\mathrm{HOC}_{2} \mathrm{H}_{4} \mathrm{~N}\left(\mathrm{CH}_{3}\right)_{3} \mathrm{Cl}\right)$ $(\mathrm{ChCl})$ (Aldrich, 99\%), ethylene glycol (EG) (Aldrich, 99.5\%), tin chloride $\left(\mathrm{SnCl}_{2} \cdot 2 \mathrm{H}_{2} \mathrm{O}\right)$ (Aldrich, 98\%) and indium chloride $\left(\mathrm{InCl}_{3}\right)$ (Aldrich, $98 \%$ ) were used as received.

The eutectic mixture (called ILEG) was prepared by mixing and heating reagents in the stated proportions at $80-100{ }^{\circ} \mathrm{C}$, with gentle stirring until a homogeneous, clear liquid was formed. 
Table 1. Electrolytes composition and operating parameters.

\begin{tabular}{ccc}
\hline Electrolyte Type & Electrolyte Composition & Temperature $/{ }^{\circ} \mathbf{C}$ \\
\hline & $0.05 \mathrm{M} \mathrm{InCl}_{3}+0.05 \mathrm{M}$ & \\
$\mathrm{SnCl}_{2} \cdot 2 \mathrm{H}_{2} \mathrm{O}$ & \\
& $0.1 \mathrm{M} \mathrm{InCl}_{3}+0.05 \mathrm{M}$ & \\
& $\mathrm{SnCl}_{2} \cdot 2 \mathrm{H}_{2} \mathrm{O}$ & \\
& $0.1 \mathrm{M} \mathrm{InCl}_{3}+0.03 \mathrm{M}$ & \\
ILEG-SnIn & $\mathrm{SnCl}_{2} \cdot 2 \mathrm{H}_{2} \mathrm{O}$ & \\
& in ILEG & \\
& & \\
\end{tabular}

Bulk electrodeposition of the Sn-In alloys has been performed under mild stirring and galvanostatic (current control) conditions using a DC/pulse reverse power supply (pe86CB 3HE, Plating Electronic $\mathrm{GmbH}$, Sexau, Germany) and a two-electrode cell configuration. The copper metallic substrates used $(70 \mathrm{~mm} \times 35 \mathrm{~mm} \times 0.2 \mathrm{~mm}$ ) were initially subjected to a mechanical polishing using 1000 and 2000 abrasive paper, followed by chemical pickling in 1:1 $\mathrm{HNO}_{3}: \mathrm{H}_{2} \mathrm{O}$ solution at $25^{\circ} \mathrm{C}$ for $20-30 \mathrm{~s}$, then rinsed with running water and distilled water and air dried. Platinized titanium plates were used as anodes. Current densities between 1 and $25 \mathrm{~mA} \mathrm{~cm}^{-2}$ and electrolyte temperatures between $25-65{ }^{\circ} \mathrm{C}$ were applied for electrodeposition durations between 20 and $60 \mathrm{~min}$.

The morphology and elemental composition of the deposited Sn-In alloys were examined using scanning electron microscopy (SEM) associated with energy-dispersive X-ray spectroscopy (EDX) (SU8230, HITACHI High-Technologies Corp., Tokyo, Japan equipped with EDX Oxford detector analyzer). The phase composition and structure were determined involving $\mathrm{X}$-ray diffractometry (XRD) (High Resolution SmartLab X-ray diffractometer Rigaku, Tokyo, Japan 9 kW, with rotating anode) using $\mathrm{CuK} \alpha$ radiation, at a speed of $2 \mathrm{~s} / \mathrm{step}\left(1 \mathrm{step}=0.05^{\circ}\right)$.

Thermogravimetric analysis (TGA) (STA 8000, Perkin Elmer, Waltham, Massachusetts, USA) was applied in order to determine the melting point of the electrodeposited alloys.

The solderability performance was assessed by dipping in molten $\mathrm{SAC} 305(\mathrm{Sn} 3.0 \mathrm{Ag} 0.5 \mathrm{Cu})$ alloy and by measurement of the angle of wettability that provides information on the degree of solder contact and strength of the solder joint, according to IPC-TM-650 [41] and IPC-610E [42] procedures.

The corrosion behavior of the electrodeposited Sn-In alloy coatings was assessed involving accelerated laboratory tests in aerated $0.5 \mathrm{M} \mathrm{NaCl}$ aqueous solution, respectively: (i) continuous immersion at $25^{\circ} \mathrm{C}$ for $360 \mathrm{~h}$ with intermediary visual examinations, (ii) potentiodynamic polarization curves at $3 \mathrm{mV} \mathrm{s}^{-1}$ sweep rate, and (iii) electrochemical impedance spectra (EIS) at open-circuit potential. A minimum of 3 pieces of the deposited $\mathrm{Sn}-\mathrm{In}$ alloy on a copper metallic support $(70 \mathrm{~mm} \times 35 \mathrm{~mm}$ ) were subjected to immersion tests. The coating thickness was $10 \pm 2 \mu \mathrm{m}$ and it was determined according to IPC-TM-650 procedure, Method 2.2.5 [43]. The geometrical surface of working electrode in the electrochemical tests was $0.63 \mathrm{~cm}^{2}$, the counterelectrode was a Pt mesh and a $\mathrm{Ag} / \mathrm{AgCl} / \mathrm{KCl}$ sat. has been used as reference electrode. EIS spectra, recorded with $10 \mathrm{mV}$ ac voltage within $100-50 \mathrm{mHz}$ frequency range, were processed using ZView 2.4 software from Scribner Association Inc., Derek Johnson.

\section{Results and Discussion}

To synthesize the electrodeposition electrolytes having the metal concentrations according to Table 1, the corresponding amounts of $\mathrm{SnCl}_{2} \cdot 2 \mathrm{H}_{2} \mathrm{O}$ and $\mathrm{InCl}_{3}$ were added to ILEG solvent under mild stirring. All mixtures are liquid at room temperature $\left(25^{\circ} \mathrm{C}\right)$. The liquids were colorless and clear, with electrical conductivities in the range of $2-12 \mathrm{mS} \mathrm{cm}^{-1}$ for a temperature domain between 25 and $75{ }^{\circ} \mathrm{C}$. Viscosity values between 35 and $7 \mathrm{mPa} \cdot \mathrm{s}$ have been determined for the same range of temperature, quite comparable with those of the pure ILEG solvent. The determined values of activation energies for viscosity (Eq) from Arrhenius plots of viscosity vs. 1/T were around $25 \mathrm{~kJ} \cdot \mathrm{mol}^{-1}$, relatively larger than those characteristic to high temperature molten salts. 


\subsection{Sn-In Alloy Coatings Characteristics}

The Sn-In alloy electrodeposition onto a Cu substrate using ILEG-SnIn electrolyte was performed under galvanostatic conditions, for applied current densities in the range of 2-25 $\mathrm{mA} \cdot \mathrm{cm}^{-2}$, at temperatures between 25 and $65^{\circ} \mathrm{C}$, under mild stirring. Smooth, adherent gray deposits were obtained, with a semi-bright appearance. Deposition rates between 0.08 and $0.15 \mu \mathrm{m} \cdot \mathrm{min}^{-1}$ were determined for the investigated current density domain.

Figure 1 shows examples of the $\mathrm{Sn}$-In alloy morphologies for different electrolyte compositions and current density values, at a temperature of $60^{\circ} \mathrm{C}$.
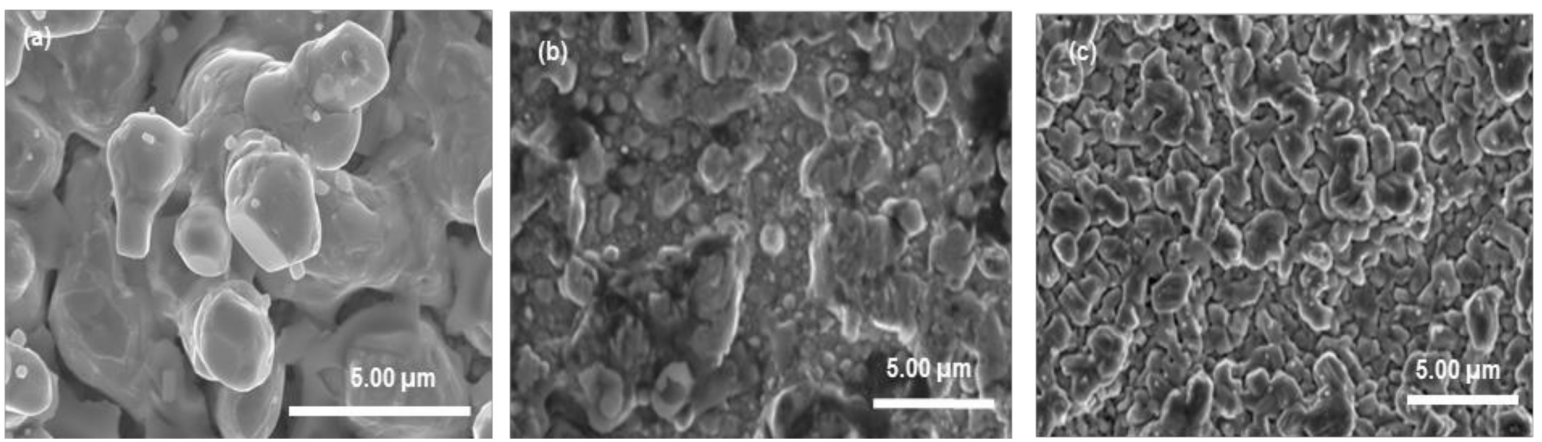

Figure 1. Scanning electron microscope (SEM) micrographs of Sn-In alloy electrodeposited from ILEG-SnIn system at $60{ }^{\circ} \mathrm{C}$ containing: (a) $50 \mathrm{mM} \mathrm{InCl}_{3}+50 \mathrm{mM} \mathrm{SnCl}_{2}, 2.5 \mathrm{~mA} \cdot \mathrm{cm}^{-2}$; (b) $100 \mathrm{mM} \mathrm{InCl}_{3}$ + $30 \mathrm{mM} \mathrm{SnCl}_{2}, 2.5 \mathrm{~mA} \cdot \mathrm{cm}^{-2}$; (c) $100 \mathrm{mM} \mathrm{InCl}_{3}+30 \mathrm{mM} \mathrm{SnCl}_{2}, 10 \mathrm{~mA} \cdot \mathrm{cm}^{-2}$ (Cu metallic substrate).

As shown in this Figure, the surface morphology depends on both the concentration of the metallic species in the electrolyte and on the applied current density. Generally, the Sn-In alloy deposit was quite homogeneous, consisting of irregular tetragonal-like particles of about 1-2.5 $\mu \mathrm{m}$, entirely covering the metallic substrate. As the In:Sn molar ratio of salts in the electrolyte increased (higher In content) at a constant applied current density the constituent particles became smaller, i.e., from the order of 2-2.5 $\mu \mathrm{m}$ for the In:Sn ratio of 1, towards 1.5-2 $\mu \mathrm{m}$ up to about 1-1.5 $\mu \mathrm{m}$ for In:Sn ratios of 2 and 3 , respectively.

This change might be related to the increase of In content in the alloy as Figure 2a below showed, which may determine the loss of their well-defined edges. In addition, the use of a higher current density determined the formation of more uniform elongated particles.
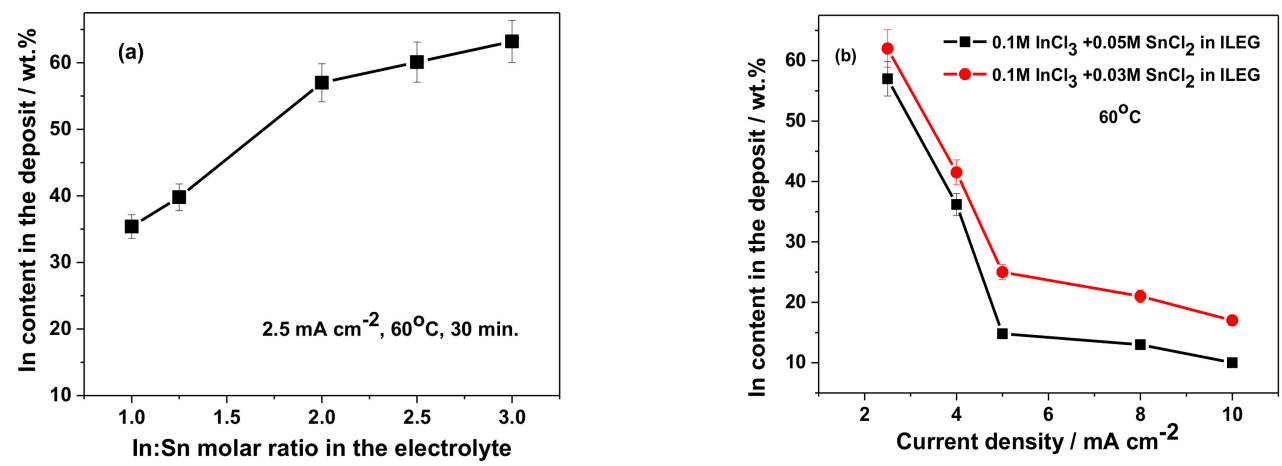

Figure 2. Cont. 


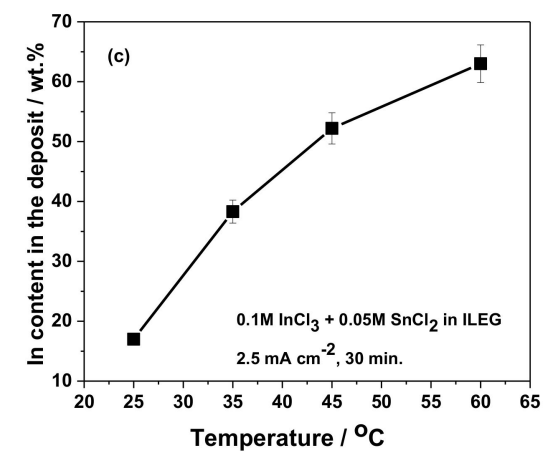

Figure 2. The influence of: (a) In:Sn molar ratio of dissolved salts in electrolyte; (b) current density; (c) temperature, on indium content within the alloy electrodeposit.

The chemical analysis of the Sn-In alloy coatings obtained was performed by EDX. The influence of the main operation parameters, respectively of the In:Sn molar ratio in the electrolyte, the current density and temperature on the indium content in the deposit is illustrated in Figure 2.

As shown in Figure 2a, the increase of In:Sn molar ratio in the electrolyte from 1.0 to 3.0 facilitated a higher In content in the deposit, from $30-35 \%$ to $60-63 \%$ (wt \%).

This behavior may be related to the influence of mass transport occurring in electrolytes with higher concentrations of $\mathrm{InCl}_{3}$. The preliminary voltammetry studies recorded on $\mathrm{Cu}$ electrode (not shown here) revealed that the deposition potential of In metal is more negative than that of Sn metal, suggesting that an In(III) concentration higher than that of Sn(II) in the bath may determine an increased In content in the alloy.

A decrease of the In content vs. the applied current density was also observed for two constant values of the In:Sn molar ratios in the bath, respectively from $55-60 \%$ In at $2.5 \mathrm{~mA} \cdot \mathrm{cm}^{-2}$ to around $12-20 \%$ In at $10 \mathrm{~mA} \cdot \mathrm{cm}^{-2}$, at $60^{\circ} \mathrm{C}$ (Figure 2b). According to Alcanfor et al. [35], the diffusion coefficient of $\mathrm{In}^{3+}$ in choline chloride-ethylene glycol is in the range $3.7-5.8 \times 10^{-12} \mathrm{~m}^{2} \cdot \mathrm{s}^{-1}$, one order of magnitude lower as compared to the diffusion coefficient of $\mathrm{Sn}^{2+}$, of about $1.96 \times 10^{-11} \mathrm{~m}^{2} \cdot \mathrm{s}^{-1}$ as reported by Ghosh et al. [44] in the same DES. Therefore, as the applied current density increased, the amount of tin species transported to the cathode surface will be higher, thus determining an enrichment of $S n$ content in the alloy.

Higher values of the applied temperature, facilitate an increased content of In in the alloy, which was more pronounced in the temperature range of $25-40^{\circ} \mathrm{C}$, as illustrated in Figure 2c. This behavior is determined by the decrease of the viscosity of the electrolyte with the temperature, which consequently facilitates a faster diffusion of the In(III) species towards the electrode surface, thus producing an increased In content in the alloy [35]. This behavior is also in agreement with findings in references [15,22] during Sn-In alloy electrodeposition from aqueous sulfate electrolytes.

In order to improve the quality of the electrodeposited Sn-In alloy coatings from morphological and homogeneity viewpoints, the use of pulsed current (PC) was also explored.

It is known that the PC may have a beneficial influence on morphology, microstructure, ductility, hardness of the electrodeposited layers while allowing higher values of the applied current density. The use of PC during electrodeposition processes in DESs based electrolytes has been scarcely reported. Maharaja et al. [45] reported the use of PC for $\mathrm{Cr}$ and $\mathrm{Cr} /$ single-walled carbon nanotubes (SWCNT) composite coatings deposition from a DES consisting of choline chloride, $\mathrm{CrCl}_{3} \cdot 6 \mathrm{H}_{2} \mathrm{O}$, ethylene glycol and $\mathrm{KCl}$ with additions of $2 \mathrm{~g} \cdot \mathrm{L}^{-1}$ SWCNT A more uniform $\mathrm{Cr}$ nanostructured deposit, with a much more uniform incorporation of SWCNT in the coating has been evidenced on applying PC. Manolova et al. [46,47] applied PC during Pd and Pd-Ag alloy electrodeposition from choline chloride:urea eutectic mixtures, also in the presence of different additives. SEM investigations have shown that the use of PC facilitated an increased metal deposition rate and improved the quality of the deposited Pd and Pd-Ag layers. 
Under these circumstances, several experiments were performed in order to explore the influence of PC on the characteristics of the electrodeposited Sn-In alloy coatings. The square-wave current pulses used in the PC experiments had average current densities between 5 and $25 \mathrm{~mA} \cdot \mathrm{cm}^{-2}$ and on-/off-times of ton/toff $=50 \mathrm{~ms} / 50 \mathrm{~ms}$.

Figure 3 presents an example of the obtained morphology of Sn-In alloy deposit under the aforementioned PC conditions and the spatial distribution profiles for the main elemental components.

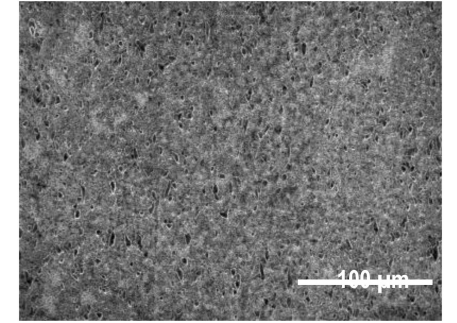

(a)

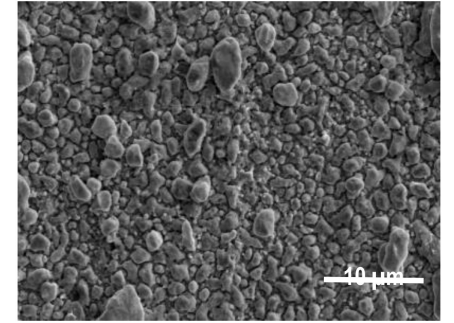

(b)

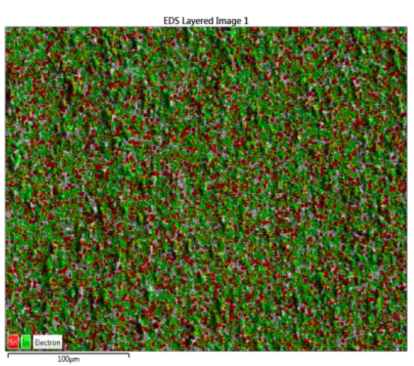

(c)

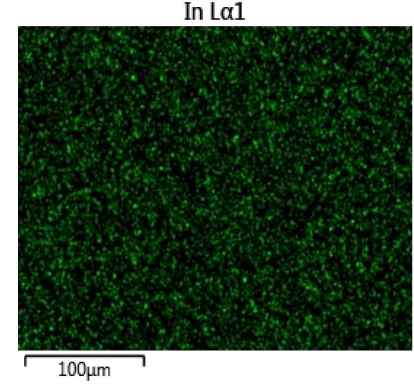

(d)

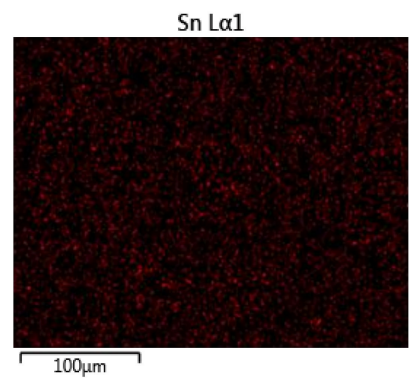

(e)

Figure 3. SEM micrographs of Sn-In alloy electrodeposited from ILEG-SnIn system at $60{ }^{\circ} \mathrm{C}$ containing: $100 \mathrm{mM} \mathrm{InCl} \mathrm{m}_{3}+50 \mathrm{mM} \mathrm{SnCl} \mathrm{m}_{2}, 10 \mathrm{~mA} \cdot \mathrm{cm}^{-2} \mathrm{t}_{\mathrm{on}}=\mathrm{t}_{\text {off }}=50 \mathrm{~ms}(\mathrm{Cu}$ metallic substrate: (a), (b) SEM images at different magnifications; (c) energy-dispersive $\mathrm{X}$-ray spectroscopy (EDX) maps of elemental distribution for: In (d) and Sn (e).

As shown in this Figure, the use of the PC led to a more homogeneous and compact deposit as compared to direct current conditions with a slight decrease of the particles size up to 1-1.2 $\mu \mathrm{m}$ Moreover, as illustrated by EDX maps, the alloying elements are uniformly distributed in the coating.

Figure 4 presents the dependence of the indium content in the deposit against the applied average current density under PC conditions.

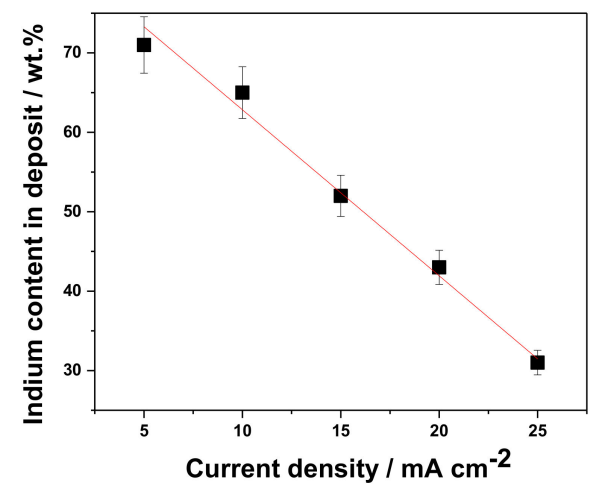

Figure 4. Dependence of the indium content in In-Sn alloy deposits vs. average applied current density from $100 \mathrm{mM} \mathrm{InCl}_{3}+50 \mathrm{mM} \mathrm{SnCl}_{2}$, at $60^{\circ} \mathrm{C}$ under pulsed current $(\mathrm{PC})$ conditions, $\mathrm{t}_{\mathrm{on}}=\mathrm{t}_{\mathrm{off}}=50 \mathrm{~ms}$. 
A relatively linear decrease of the indium percentage with the current density increase was noticed, in a quite similar manner evidenced under direct current electrodeposition conditions. However both the range of indium content and of the current density were larger when PC was used.

XRD analysis was applied to get information on the present phases in the electrodeposited In-Sn alloy films. Figure 5 presents a typical X-ray pattern of the In-Sn alloy obtained involving an ILEG-SnIn electrolyte containing $50 \mathrm{mM} \mathrm{InCl}_{3}+50 \mathrm{mM} \mathrm{SnCl}_{2}$.

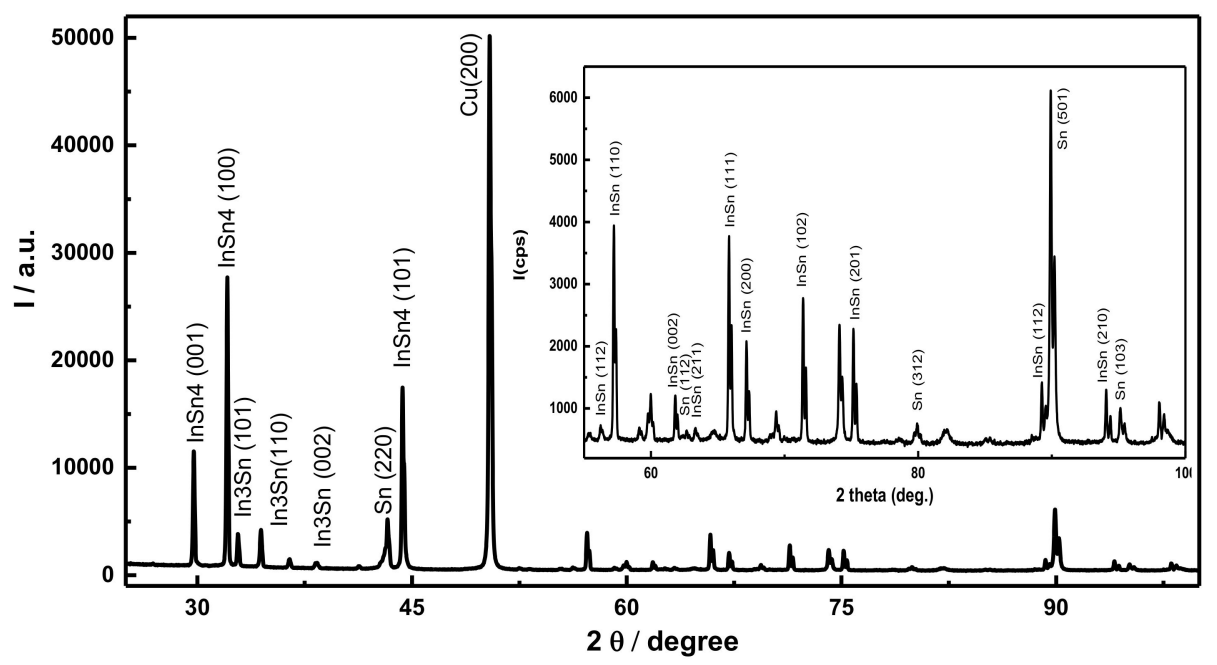

Figure 5. X-ray diffraction (XRD) patterns of Sn-In alloy coating electrodeposited from ILEG based system containing $50 \mathrm{mM} \mathrm{InCl}_{3}+50 \mathrm{mM} \mathrm{SnCl}_{2}$, at $60{ }^{\circ} \mathrm{C}$ and $2.5 \mathrm{~mA} \cdot \mathrm{cm}^{-2}$. Inset: the enlargement of the region corresponding to $2 \theta$ between $60^{\circ}$ and $100^{\circ}$.

The presence of $\mathrm{InSn}_{4}$ phase (with characteristic peaks at $29.76^{\circ}, 32.1^{\circ}, 44.34^{\circ}, 57.23^{\circ}, 61.83^{\circ}$, $65.85^{\circ}, 71.39^{\circ}, 79.92^{\circ}$ ) and In3Sn phase (characteristic peaks at la $32.83^{\circ}, 36.52^{\circ}, 41.29^{\circ}, 56.23^{\circ}, 63.34^{\circ}$ ) was identified, with some Sn traces.

As Figure 5 shows, the diffraction peaks which are associated with (001), (100) and (101) diffraction planes of hexagonal $\mathrm{InSn}_{4}$ (PDF Card No. 01-077-2746) are the most intense. In addition, diffraction peaks corresponding to (101), (110) and (002) planes with smaller intensities corresponding to tetragonal $\mathrm{In}_{3} \mathrm{Sn}$ (PDF Card No. 01-077-2749) were also detected, along with some peaks of the Sn traces and Cu substrate.

It is worth mentioning that the phase composition of the Sn-In alloy coatings remained the same for the investigated electrodeposition conditions.

Quite similar XRD patterns were reported in $[38,39]$ for In-Sn alloy layers electrodeposited in EMI-BF 4 -CI melts.

TGA analysis was used to get information on the melting point of the electrodeposited In-Sn alloys. Figure 6 illustrates examples of the recorded TGA curves for different In-Sn alloys electrodeposited both under direct current and PC conditions. The electrodeposition was carried out on Ti substrate that further allowed the easy detaching of the alloy. 


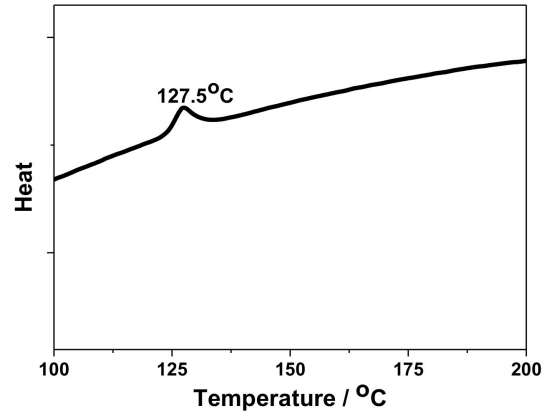

(a)

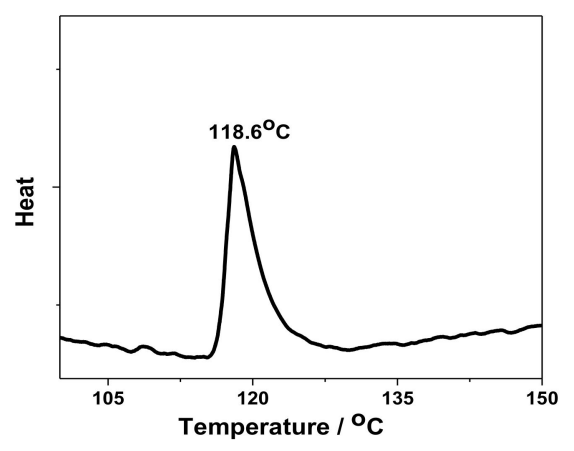

(b)

Figure 6. Thermogravimetric analysis (TGA) for In-Sn alloy electrodeposited from ILEG-InSn electrolyte containing: (a) $100 \mathrm{mM} \mathrm{InCl}{ }_{3}+30 \mathrm{mM} \mathrm{SnCl}_{2}, 3 \mathrm{~mA} \cdot \mathrm{cm}^{-2}$ (direct current, Ti substrate) and (b) $50 \mathrm{mM}$ $\mathrm{InCl}_{3}+50 \mathrm{mM} \mathrm{SnCl} 2,20 \mathrm{~mA} \cdot \mathrm{cm}^{-2}$ (pulsed current, Ti substrate).

As shown in Figure 6, melting temperatures of $127.5^{\circ} \mathrm{C}$ and of $118.6^{\circ} \mathrm{C}$ were determined quite close to the values corresponding to 50In-50Sn and to 52In-48Sn lead free solders [48].

\subsection{Solderability Tests}

To obtain preliminary information on the reliability of the In-Sn alloys as solder joints the applied procedure followed the steps according to [41,42]. Consequently, the pre-coated with In-Sn alloy specimens were subjected to immersion in molten SAC 305 alloy for $10 \mathrm{~s}$ at $245^{\circ} \mathrm{C}$. After dipping in solder bath, the specimen surface was assessed visually for evidence of the non-wetting and de-wetting areas. In addition, the wetting angle was determined, which is an indicator of the degree of solder contact and strength of the solder joint.

Figure 7 presents images of the wetting angle formed between the SAC 305 alloy and In-Sn alloy coating after reflow at $245^{\circ} \mathrm{C}$ as well as of the sample surface mounted printed circuit boards (PCBs) and microsection through the solder joint on the PCB pre-coated with Sn-In alloy.

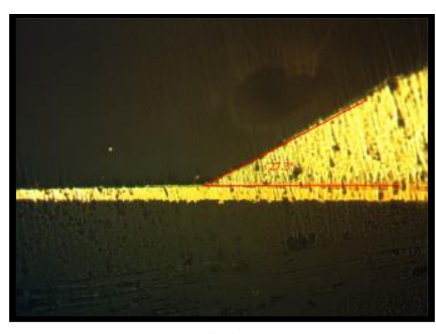

(a)

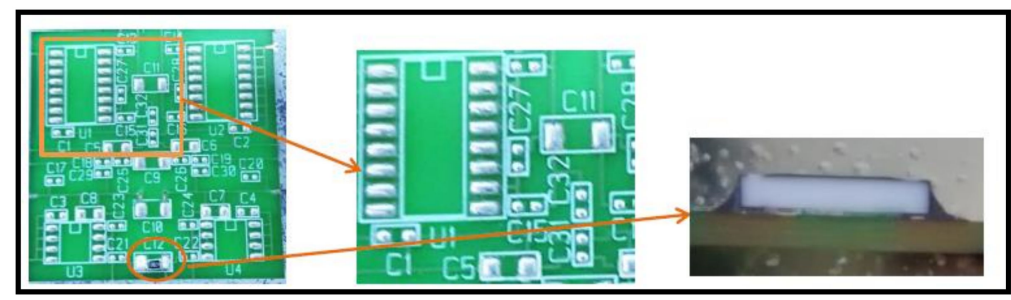

(b)

Figure 7. (a) Optical micrograph of the prepared microsection for the measurement of the wetting angle formed between the SAC 305 alloy and In-Sn alloy coating after reflow at $245{ }^{\circ} \mathrm{C}$; (b) images of the sample surface mounted PCBs and microsection through the solder joint on the PCB pre-coated with Sn-In alloy.

As exemplified in this figure, wetting angles around $27^{\circ}$ were determined, less than $90^{\circ}$, suggesting proper solderability characteristics. However, the visual examination evidenced the presence of some nonwetting and dewetting areas which might be due to the possible presence of oxides on the alloy surface before immersion in the molten SAC alloy.

As shown in Figure $7 \mathrm{~b}$, the solder joints showed a proper adhesion to the substrate with no fractures. These findings suggest that the $\mathrm{Sn}-\mathrm{In}$ alloy coatings ensure a suitable bonding with the solder paste material. 


\subsection{Corrosion Behavior of Sn-In Alloy Coatings Obtained from Deep Eutectic Solvents (DESs)}

Potentiodynamic polarization curves (not shown here) and electrochemical impedance spectra (EIS) at open circuit potential, in a free-aerated $0.5 \mathrm{M} \mathrm{NaCl}$ aqueous solution at room temperature, after different immersion periods were recorded to obtain information on the corrosion performance of the obtained Sn-In alloys coatings.

The EIS spectra of Sn-In alloy coatings recorded at open circuit potential (OCP) in $0.5 \mathrm{M}$ $\mathrm{NaCl}$ solution for different immersion periods are shown in Figure 8, as Nyquist and Bode plots. The equivalent circuit to describe corrosion behavior of $\mathrm{Sn}$-In alloy deposits in the $\mathrm{NaCl}$ solution is shown in Figure 8c.

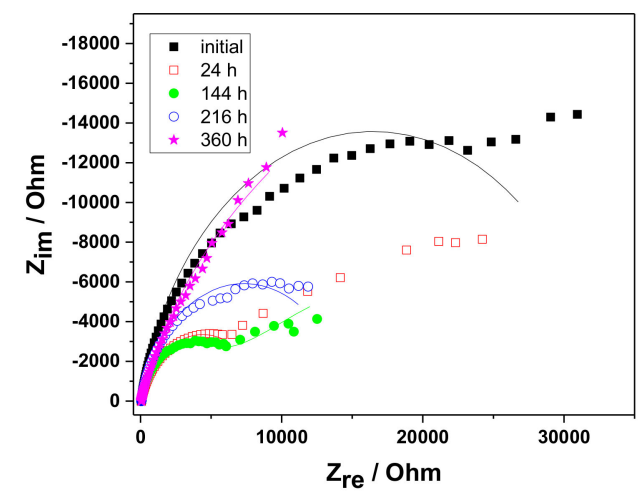

(a)

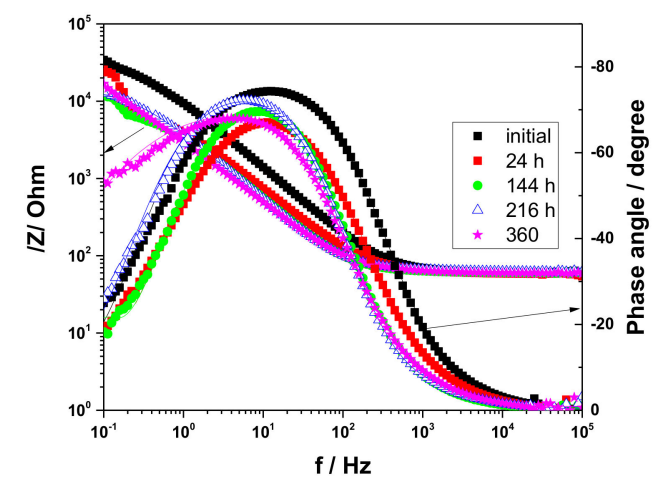

(b)

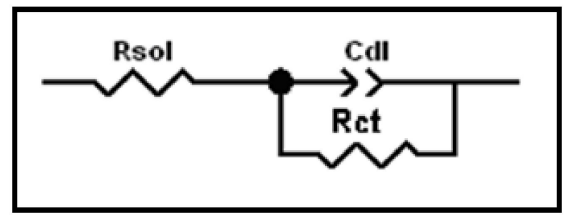

(c)

Figure 8. Nyquist (a) and Bode (b) plots for Sn-In alloy coating in $0.5 \mathrm{M} \mathrm{NaCl}$ at open circuit potential, after various continuous immersion periods (solid lines are the fit of the measured points using the equivalent circuit shown in (c).

All Nyquist diagrams show a semi-circle arc in the relative high-frequency range. The semicircles continue in low fequencies with almost linear portion indicating the formation of an adherent layer of corrosion products. The diameter of the semicircles is associated with the polarization resistance (charge transfer resistance, $\mathrm{R}_{\mathrm{ct}}$ ) which may be correlated to the rate of corrosion: the larger the resistance, the lower the corrosion current. All Bode diagrams indicate a single time constant for corrosion kinetics, with the maximum modulus of impedance $(|\mathrm{Z}|)$ at lowest frequencies having values of ca 10,000-30,000 $\Omega$. Also, the maximum of the phase angle curves is recorded at $10-30 \mathrm{~Hz}$ frequency. It started from $-75^{\circ}$, decreased suddenly to $-67^{\circ}$ after $24 \mathrm{~h}$ immersion and then increased (in 24-216 $\mathrm{h}$ period) and decreased (in $216-360 \mathrm{~h}$ period) within this range of values.

The process can be modeled as an ohmic resistance of solution $\left(R_{\text {sol }}\right)$ in series with a parallel circuit consisting in a double-layer capacitor $\left(\mathrm{C}_{\mathrm{dl}}\right)$ and a charge-transfer resistor $\left(\mathrm{R}_{\mathrm{ct}}\right)$. During the fitting of the experimental data a constant phase element (CPE) was used instead of true capacitance (Cdl) [49], in order to model more accurately the non-ideal behavior of $C_{\mathrm{dl}}$ capacitance.

In Table 2 the resulting values of the charge-transfer resistance $\left(R_{c t}\right)$ for the corrosion of Sn-In alloy are presented, which were obtained by fitting the impedance data with ZView software. It can be seen that $R_{\mathrm{ct}}$ decreased from an initial value of about $32.8 \mathrm{k} \Omega$ towards $7.6 \mathrm{k} \Omega$ after $144 \mathrm{~h}$ of conditioning. The semicircle diameter (which corresponds to $R_{\mathrm{ct}}$ ) decreased faster in time in the first $24 \mathrm{~h}$ period 
indicating an intense corrosion, probably due to the activation of some defects. During the period 24-144 $\mathrm{h}$ this decrease of $\mathrm{R}_{\mathrm{ct}}$ was slowed down due to formation of a less porous layer that still allows $\mathrm{Cl}^{-}$ions penetration to $\mathrm{Sn}-\mathrm{In}$ alloy surface.

Table 2. Values of $\mathrm{R}_{\mathrm{CT}}$ by fitting impedance results for $\mathrm{Sn}$-In alloy coating after exposure to $0.5 \mathrm{M} \mathrm{NaCl}$ solution for different times using the equivalent circuit proposed in Figure 8c.

\begin{tabular}{cc}
\hline Immersion Time/h & $\mathbf{R}_{\mathbf{c t}} / \mathbf{\Omega}$ \\
\hline 0 & 32,807 \\
24 & 8715 \\
144 & 7658 \\
216 & 14,290 \\
360 & 34,607 \\
\hline
\end{tabular}

It follows a corrosion step (144-360 h) when $R_{\text {ct }}$ increased, indicating the thickening the layer of corrosion products on the Sn-In surface, so that it may act as a passive layer, with protective behavior restored.

\section{Conclusions}

As a result of the investigations performed, several electrochemical procedures to prepare adherent and uniform Sn-In alloys containing 10-65 wt.\% In from choline chloride-ethylene glycol eutectic mixtures were proposed. The In content was found to increase as both the In:Sn molar concentration ratio of ionic species in the electrolyte and the applied temperature increased.

SEM micrographs of the electrodeposited alloy coatings evidenced the presence of quite irregular particles entirely covering the metallic substrate under direct current plating conditions, while a more homogeneous and compact deposit, with a slight decrease of the particles size, was obtained using PC. In addition, the pulsed current procedure allowed the use of higher current densities leading to slightly higher values of In content in the alloy deposit.

The XRD analysis revealed the presence of $\mathrm{InSn}_{4}$ and $\mathrm{In}_{3} S \mathrm{Sn}$ phases in agreement with the phase diagram. According to the TGA measurements, melting points in the range of 118.6 and $127.5^{\circ} \mathrm{C}$ were obtained, depending on the alloy composition.

The obtained results showed adequate solderability performance and a good corrosion performance. After $360 \mathrm{~h}$ of continuous immersion in chloride containing aggresive medium, the exposed specimens did not exhibit any major surface modification.

While this study showed that the electrodeposition of Sn-In alloy coatings from DESs is possible, more investigations are needed to gain a better understanding of this alloy deposition mechanism with direct impact on its composition and application in various domains, including electronic industry. The results of this study will be presented in a separate manuscript.

Author Contributions: Conceptualization, writing-original draft preparation, corrosion experiments and analysis L.A.; electrodeposition methodology and experiments, analysis A.P.; electrodeposition experiments, solderability methodology, testing and analysis, S.C.; TGA measurements and analysis, C.M.; SEM, XRD. investigation and analysis, O.B.; writing — review and editing, visualization, T.V.

Funding: This research work was funded by Romanian Ministry of Education and by Executive Agency for Higher Education, Research, Development and Innovation Funding, under NOVTINALBEST project 38/2016, M Era Net Program and under ROFCC project, Contract No. 25 PCCDI/2018.

Acknowledgments: The authors would like to thank to M. Enachescu for technical support and assistance in the films characterization (SEM, XRD, TGA).

Conflicts of Interest: The authors declare no conflict of interest. 


\section{References}

1. Directive 2002/95/EC of the European Parliament and of the Council. Available online: http://eurlex.europa. eu/LexUriServ/LexUriServ.do?uri=OJ:L:2003:037:0019:0023:EN:PDF (accessed on 25 October 2019).

2. Cheng, S.; Huang, C.M.; Pecht, M. A review of lead-free solders for electronic applications. Microelectron. Reliab. 2017, 75, 77-95. [CrossRef]

3. Qin, Y.; Wilcox, G.D.; Liu, C. Electrodeposition and characterisation of Sn-Ag-Cu solder alloys for flip-chip interconnection. Electrochim. Acta 2010, 56, 183-192. [CrossRef]

4. Huang, J.T.; Chao, P.S.; Hsu, H.J.; Shih, S.H. A novel bumping process for fine pitch Sn-Cu lead-free plating-based flip chip solder bumps. Mater. Sci. Semicond. Process. 2007, 10, 133-142. [CrossRef]

5. Yingxin, G.; Haseeb, A.S.M.A.; Sabri, M.F.M. Electrodeposition of lead-free solder alloys. Solder. Surf. Mt. Technol. 2013, 25, 76-90.

6. Wislei, R.O.; Leandro, C.P.; Lenoardo, R.G.; Nathalie, M.; Amauri, G. Microstructure and mechanical properties of Sn-Bi, Sn-Ag and Sn-Zn lead-free solder alloys. J. Alloy. Compd. 2013, 572, 97-106.

7. Zhang, R.; Zhang, J.; Evans, J.; Johnson, W.; Vardaman, J.; Fujimura, I.; Tseng, A.; Knight, J. Tin-Bismuth Plating for Component Finishes. In Proceedings of the IEEE 61st Electronic Components and Technology Conference (ECTC), Lake Buena Vista, FL, USA, 31 May-3 June 2011; pp. 2060-2066.

8. Liu, L.; Xue, S.; Liu, S. Mechanical Property of Sn-58Bi Solder Paste Strengthened by Resin. Appl. Sci. 2018, 8, 2024. [CrossRef]

9. Das Mahapatra, S.; Dutta, I. Co-electrodeposition of tin with $0.2-20 \%$ indium: Implications on tin whisker growth. Surf. Coat. Technol. 2018, 337, 478-483. [CrossRef]

10. Jadhav, N.; Williams, M.; Pei, F.; Stafford, G.; Chason, E. Altering the mechanical properties of Sn films by alloying with Bi: Mimicking the effect of $\mathrm{Pb}$ to suppress whiskers. J. Electron. Mater. 2013, 42, 312-318. [CrossRef]

11. Dimitrovska, A.; Kovacevic, R. The effect of micro-alloying of Sn plating on Sn whisker growth. J. Electron. Mater. 2009, 38, 2726-2734. [CrossRef]

12. Leidecker, H.; Kadesch, J.S. Effects of Uralane conformal coating on tin whisker growth. In Proceedings of the 37th IMAPS Nordic Annual Conference, Helsingor, Denmark, 10-13 September 2000; pp. 108-116.

13. Meinshausen, L.; Bhassyvasantha, S.; Majumdar, B.S.; Dutta, I. Influence of indium addition on whisker mitigation in electroplated tin coatings on copper substrates. J. Electron. Mater. 2016, 45, 791-801. [CrossRef]

14. Das Mahapatra, S.; Majumdar, B.S.; Dutta, I.; Bhassyvasantha, S. Elimination of whisker growth in tin coatings by indium addition. J. Electron. Mater. 2016, 46, 4062-4075. [CrossRef]

15. Medvedev, G.I.; Rybin, A.A.; Makrushin, N.A. Electrodeposition of tin-indium alloy from a sulfate electrolyte in the presence of organic substances. Russ. J. Appl. Chem. 2012, 85, 604-611.

16. Nawafune, H.; Nakatani, T.; Akamatsu, K.; Mizumoto, S.; Obata, K.; Uchida, E. Electrodeposition of Sn-In Eutectic Alloy from Sulfosuccinate Bath for Flip-Chip Interconnection. Mater. Sci. (Jpn.) 2002, 5, 349-352.

17. Qin, Y.; Flajslik, K.; Sherzer, B.; Banelis, E.; Lee, I.; Cho, R.; Grippo, L.; Imanari, M.; Lefebvre, M.; Wei, L.; et al. Enabling Low-Temperature Bonding in Advanced Packaging using Electrodeposited Indium. In Proceedings of the IEEE 66th Electronic Components and Technology Conference (ECTC), Las Vegas, NV, USA, 31 May-3 June 2016; pp. 2151-2156.

18. Lyon, S.B. Corrosion of tin and its alloys. In Shreir's Corrosion, 4th ed.; Elsevier B.V.: Amsterdam, The Netherland, 2010; Volume 3, pp. 2068-2077.

19. Kim, H.; Lee, H.; Lim, T.; Ahn, S.H. Facile fabrication of porous Sn-based catalysts for electrochemical $\mathrm{CO}_{2}$ reduction to $\mathrm{HCOOH}$ and syngas. J. Ind. Eng. Chem. 2018, 66, 248-253. [CrossRef]

20. Lai, Q.; Yang, N.; Yuan, G. Highly efficient In-Sn alloy catalysts for electrochemical reduction of $\mathrm{CO}_{2}$ to formate. Electrochem. Commun. 2017, 83, 24-27. [CrossRef]

21. Ota, J.; Ishikawa, K.; Kosakai, K. Plating of indium-tin alloy. J. Metal Finish. Soc. Jpn. 1965, 16, $246-250$. [CrossRef]

22. Medvedev, G.I.; Rybin, A.A.; Makrushin, N.A. Leveling power of sulfate electrolytes with organic in electrodeposition of tin-indium alloy. Russ. J. Appl. Chem. 2013, 86, 351-354.

23. Ozga, P.; Swiatek, Z.; Michalec, M.; Onderka, B.; Bonarski, J. Phase structure and texture of electrodeposited InSn alloys on copper substrate. Arch. Metall. Mater. 2008, 53, 307-315. 
24. Shaban, M.; Kholidy, I.; Ahmed, G.M.; Negem, M.; Abd El-Salam, H.M. Cyclic voltammetry growth and characterization of $\mathrm{Sn}-\mathrm{Ag}$ alloys of different nanomorphologies and compositions for efficient hydrogen evolution in alkaline solutions. RSC Adv. 2019, 9, 22389-22400. [CrossRef]

25. Abbott, A.P.; Alhaji, A.I.; Ryder, K.S.; Horne, M.; Rodopoulos, T. Electrodeposition of copper-tin alloys using deep eutectic solvents. Trans. IMF 2016, 94, 104-113. [CrossRef]

26. Endres, F.; Abbott, A.P.; MacFarlane, D.R. Electrodeposition of Metals Using Ionic Liquids; Wiley-VCH: Weinheim, Germany, 2008.

27. Wang, P.K.; Lin, W.J.; Sun, I.W. A glance of the electrochemical co-deposition of indium and arsenic in a choline chloride/ethylene glycol deep eutectic solvent. J. Electrochem. Soc. 2019, 166, D374-D380. [CrossRef]

28. Abbott, A.P.; Boothby, D.; Capper, G.; Davies, D.L.; Rasheed, R.K. Deep eutectic solvents formed between choline chloride and carboxylic acids: Versatile alternatives to ionic liquids. J. Am. Chem. Soc. 2004, 126, 9142-9147. [CrossRef] [PubMed]

29. Abbott, A.P.; Boothby, D.; Capper, G.; Davies, D.L.; Rasheed, R.K. Ionic liquid analogues formed from hydrated metal salts. Chem. Eur. J. 2004, 10, 3769-3774. [CrossRef] [PubMed]

30. Abbott, A.P.; McKenzie, K.J. Application of ionic liquids to the electrodeposition of metals. Phys. Chem. Chem. Phys. 2006, 8, 4265-4279. [CrossRef] [PubMed]

31. Gao, Y.; Hu, W.; Gao, X.; Duan, B. Electrodeposition of SnBi coatings based on deep eutectic solvent. Surf. Eng. 2014, 30, 59-63. [CrossRef]

32. Anicai, L.; Petica, A.; Costovici, S.; Prioteasa, P.; Visan, T. Electrodeposition of Sn and NiSn alloys coatings using choline chloride based ionic liquids-Evaluation of corrosion behavior. Electrochim. Acta 2013, 114, 868-877. [CrossRef]

33. Abbott, A.P.; Capper, G.; McKenzie, K.J.; Ryder, K.S. Electrodeposition of zinc-tin alloys from deep eutectic solvents based on choline chloride. J. Electroanal. Chem. 2007, 599, 288-294. [CrossRef]

34. Barrado, E.; Garcia, S.; Rodriguez, J.A.; Castrillejo, Y. Electrodeposition of indium on W and Cu electrodes in the deep eutectic solvent choline chloride-ethylene glycol (1:2). J. Electroanal. Chem. 2018, 823, 106-120. [CrossRef]

35. Alcanfor, A.A.C.; dos Santos, L.P.M.; Dias, D.F.; Correia, A.N.; de Lima-Neto, P. Electrodeposition of indium on copper from deep eutectic solvents based on choline chloride and ethylene glycol. Electrochim. Acta 2017, 235, 553-560. [CrossRef]

36. Malaquias, J.C.; Steichen, M.; Thomassey, M.; Dale, P.J. Electrodeposition of Cu-In alloys from a choline chloride based deep eutectic solvent for photovoltaic applications. Electrochim. Acta 2013, 103, 15-22. [CrossRef]

37. Malaquias, J.C.; Steichen, M.; Dale, P.J. One-step electrodeposition of metal precursors from a deep eutectic solvent for $\mathrm{Cu}$ (In, Ga) $\mathrm{Se}_{2}$ thin film solar cells. Electrochim. Acta 2015, 151, 150-156. [CrossRef]

38. Nakahara, Y.; Morimitsu, M.; Matsunaga, M. Electrodeposition of In-Sn alloys in EMI-BF4-Cl molten salts. In Proceedings of the Electrochemical Society, 206th ECS Meeting, Honolulu, HI, USA, 3-8 October 2004; Volume 2004, pp. 861-865.

39. Morimitsu, M.; Nakahara, Y.; Matsunaga, M. Electrodeposition of In-Sn alloys from EMI-BF4-Cl melts. Electrochemistry 2005, 73, 754-757. [CrossRef]

40. Noda, M.; Morimitsu, M.; Matsunaga, M. Electrodeposition of In-Sn alloys in EMI-BF4-Cl ambient temperature melts with current pulses. ECS Trans. 2007, 3, 249-252.

41. IPC-TM-650 Procedure 2.1.1 rev.F- Micro-Sectioning. Available online: http://www.ipc.org/TM/2-1-01F.pdf (accessed on 25 October 2019).

42. IPC-610E- Acceptability of Electronic Assemblies. Available online: http://www.ipc.org/TOC/IPC-A-610E.pdf (accessed on 25 October 2019).

43. IPC-TM-650, Method 2.2.5 -Dimensional Inspections Using Microsections. Available online: http://www.flexplus.com/Upload/\%E4\%B8\%8B\%E8\%BD\%BD\%E4\%B8\%AD\%E5\%BF\%83/IPCTM650-14370777531.pdf (accessed on 20 November 2019).

44. Ghosh, S.; Ryder, K.; Roy, S. Electrochemical and transport properties of ethaline containing copper and tin chloride. Trans. IMF 2013, 92, 41-46. [CrossRef]

45. Maharaja, J.; Raja, M.; Mohan, S. Pulse electrodeposition of Cr-SWCNT composite from choline chloride based electrolyte. Surf. Eng. 2014, 30, 722-727. [CrossRef] 
46. Manolova, M.; Böck, R. Electrodeposition of Pd from a deep eutectic solvent system: Effect of additives and hydrodynamic conditions. Trans. IMF 2019, 97, 161-168. [CrossRef]

47. Manolova, M.; Böck, R.; Scharf, I.; Mehner, T.; Lampke, T. Pulse plating of Pd-Ag alloy films from deep eutectic solvents. Surf. Eng. 2019, 35, 1081-1087. [CrossRef]

48. Humpston, G.; Jacobson, D.M. Indium solders. Adv. Mater. Proc. 2005, 4, 45-47.

49. Osórioa, W.R.; Spinelli, J.E.; Afonso, C.R.M.; Peixoto, L.C.; Garcia, A. Microstructure, corrosion behaviour and microhardness of a directionally solidified Sn-Cu solder alloy. Electrochim. Acta 2011, 56, 8891-8899. [CrossRef]

(C) 2019 by the authors. Licensee MDPI, Basel, Switzerland. This article is an open access article distributed under the terms and conditions of the Creative Commons Attribution (CC BY) license (http://creativecommons.org/licenses/by/4.0/). 